\title{
RELATOS DE EXPERIENCIAS

\section{Inclusão escolar e atuação dos Núcleos de Apoio às Pessoas com Necessidades Educacionais Específicas no Instituto Federal de São Paulo}

Instituto Federal de São Paulo (IFSP). São Carlos, São Paulo, Brasil. E-mail: <crios@ ifsp.edu.br >; <https://orcid. org/0000-0001-6050-2369>.

II Doutora em Educação Especial pela Universidade Federal de São Carlos (UFSCar). São Carlos, São Paulo, Brasil.

III Instituto Federal de São Paulo (IFSP). Birigui, São Paulo, Brasil. E-mail: <micheleoliveira@ifsp. edu.br >, <https://orcid. org/0000-0001-5283-6924>.

IV Doutora em Educação pela Universidade Estadual Paulista (Unesp). Marília, São Paulo, Brasil.

v Universidade Federal de São Carlos (UFSCar). São Carlos, São Paulo, Brasil. E-mail: <abmomesso@ gmail.com>; <https://orcid org/0000-0002-0323-9004>.

vi Graduada em Pedagogia pela Universidade Estadual Paulista (Unesp). Bauru, São Paulo, Brasil.

VII Instituto Federal de São Paulo (IFSP). Jundiaí, São Paulo, Brasil. E-mail: $<$ gabriela.alias@ifsp. edu.br >; <https://orcid. org/0000-0002-0636-285X >.

VIII Doutora em Educação pela Universidade Estadual Paulista (Unesp). Presidente Prudente, São Paulo, Brasil.
Carla Ariela Rios Vilaronga ${ }^{\text {II }}$

Michele Oliveira da Silva ${ }^{\mathrm{II}, \mathrm{IV}}$

Ana Beatriz Momesso Franco v,vi

Gabriela Alias Rios ${ }^{\mathrm{VII}, \mathrm{VIII}}$

https://doi.org/10.24109/2176-6681.rbep.102.i260.4585

\section{Resumo}

Os Núcleos de Apoio às Pessoas com Necessidades Educacionais Específicas (Napnes) têm sido referência para a educação do estudante público-alvo da educação especial (PAEE) no contexto da Rede Profissional e Tecnológica e têm realizado diferentes ações também no contexto do Instituto Federal de Educação, Ciência e Tecnologia de São Paulo (IFSP). Dessa forma, ficam evidentes a relevância de estudos voltados ao processo de inclusão dos alunos PAEE nos institutos federais (IFs) e as questões quanto a planejamento do ensino, acessibilidade e permanência. Diante disso, o objetivo deste trabalho foi mapear e analisar ações desenvolvidas ou vivenciadas pelas equipes dos Napnes de diferentes campi do IFSP, tendo como base a proposta de atuação do núcleo da instituição. A pesquisa caracteriza-se como qualitativa, de caráter documental, sendo analisados os conteúdos da Revista Napne em Ação, que teve sua primeira edição em 2015, originada pelo relatório das atividades anuais dos campi. Foram também examinados os documentos institucionais que regularizam 
a atuação dos Napnes. As 302 páginas da revista foram tabuladas em informações quantitativas e analisadas qualitativamente, organizadas em eixos temáticos. Os dados apontam que, observando o IFSP como um todo, foram realizadas ações de ensino, pesquisa e extensão relacionadas ao estudante PAEE, cumprindo-se os objetivos da proposta do núcleo. Também foram feitas ações com as diferentes especificidades, com destaque para o estudante surdo, além daquelas de formação de servidores. Entende-se, na análise individual dos campi, que existem ações sendo realizadas e que a proposta de inclusão escolar não está estagnada desde 2014, mas não há dados para afirmar que os estudantes PAEE do IFSP têm seus direitos de acessibilidade e educação garantidos, sendo esse um limite da pesquisa.

Palavras-chave: educação especial; educação inclusiva; formação profissional.

\section{Abstract \\ Inclusive education and the activities of the assistance centers - Núcleos de Apoio às Pessoas com Necessidades Especiais - in the Federal Institute of São Paulo}

Assistance centers called Núcleos de Apoio às Pessoas com Necessidades Educacionais Específicas (Napnes) have been serving as reference in the education of students target-audience of special education (in Portuguese, estudante público-alvo da educação especial, acronymed PAEE) in the context of the Rede Profissional e tecnológica. These centers have also carried out different initiatives within the context of the Federal Institute of São Paulo (IFSP). Thus, studies on the inclusion of PAEE students on federal institutes (IFs) and on issues related to teaching planning, their accessibility and permanence prove to be the more relevant. This study aims to map and analyze initiatives developed or experienced by Napnes' teams from the different IFSP campuses, regarding the assistance center's activities proposal. This is a qualitative and documental research, and the contents of the journal titled Napne em Ação were analyzed. Its first edition was published in 2015 and was composed by the annual reports of the activities carried out in the campuses. Institutional documents which regulate the activities performed by Napnes were also analyzed. The journal's 302 pages were organized in quantitative information and analyzed qualitatively, divided in thematic axes. Data indicate that, analyzing IFSP as a whole, teaching, research and extension initiatives related to the PAEE students were carried, which fulfills the objectives in the center's activities proposal. Actions related to the different specificities were also carried out, with emphasis on deaf students, with the addition to those aimed at employee training. It is understood, through the individual analysis of each campus, that there are initiatives being carried out and that the proposal for school inclusion has not been stagnant since 2014. However, there is 
not enough data to affirm that PAEE students' rights of accessibility and education have been guaranteed, which is a limit of this research.

Keywords: inclusive education; professional training; special education.

\section{Resumen \\ Inclusión escolar y actuación de los Centros de Apoyo a las Personas con Necesidades Educativas Específicas en el Instituto Federal de São Paulo}

Los Núcleos de Apoyo a las Personas con Necesidades Educativas Específicas (Napne) han sido referencia cuando se habla del público al que se dirige la educación especial (PAEE), en el contexto de la Red Profesional y Tecnológica y han realizado también diferentes acciones dentro del Instituto Federal de Educação, Ciência e Tecnologia de São Paulo (IFSP). De esta manera, se hace evidente la relevancia de estudios que hablen sobre el proceso de inclusión de los alumnos PAEE en los Institutos Federales (IF), así como sobre la planeación de la enseñanza, accesibilidad y permanencia. Frente a este contexto, el objetivo de este trabajo fue mapear y analizar acciones desarrolladas o vividas por los equipos de los Napne de diferentes campus del IFSP, teniendo como base la propuesta de actuación del núcleo de la institución. Se trata de una investigación cualitativa, de carácter documental, en la que se analizaron los contenidos de la Revista Napne em Ação, que fue lanzada por primera vez en el 2015, originada por el informe de las actividades anuales de los campus. También fueron analizados los documentos institucionales que regularizan la actuación de los Napne. Las 302 páginas de la revista fueron tabuladas en informaciones cuantitativas y analizadas cualitativamente, organizadas en ejes temáticos. Los datos apuntan que, analizando al IFSP como un todo, se realizaron acciones de enseñanza, investigación y extensión relacionadas a los estudiantes PAEE, cumpliéndose así los objetivos de la propuesta del núcleo. También fueron realizadas acciones para diferentes especificidades, destacando las dirigidas a los estudiantes sordos, además de acciones de formación de personal administrativo. En cuanto al análisis individual de cada campus, se entiende que hay acciones que están siendo realizadas y que la propuesta de inclusión escolar no está estancada desde el 2014, sin embargo, no existen datos para afirmar que los alumnos PAEE del IFSP tengan el derecho de accesibilidad a la educación garantizado, siendo éste un límite de la investigación.

Palabras clave: educación especial; educación inclusiva; formación profesional. 


\section{Introdução}

A Lei $\mathrm{n}^{\circ}$ 13.146/2015, denominada Estatuto da Pessoa com Deficiênciaa popular Lei da Inclusão -, determina, no art. $1^{\circ}$, que seu principal objetivo é "assegurar e promover, em condições de igualdade, o exercício dos direitos e das liberdades fundamentais das pessoas com deficiência, visando à sua inclusão social e cidadania" (Brasil, 2015, art. 1). Ainda segundo essa lei, a educação é um direito de:

XIV - inclusão em conteúdos curriculares, em cursos de nível superior e de educação profissional técnica e tecnológica, de temas relacionados à pessoa com deficiência nos respectivos campos de conhecimento;

XV - acesso da pessoa com deficiência, em igualdade de condições, a jogos e a atividades recreativas, esportivas e de lazer, no sistema escolar;

XVI - acessibilidade para todos os estudantes, trabalhadores da educação e demais integrantes da comunidade escolar às edificações, aos ambientes e às atividades concernentes a todas as modalidades, etapas e níveis de ensino (Brasil, 2015, art. 28).

No entanto, a qualidade do atendimento educacional na escolarização de alunos público-alvo da educação especial (PAEE) na rede regular de ensino, na maioria dos casos, ainda está aquém do esperado, principalmente quando se tem número expressivo de matrículas de estudantes incluídos em classes comuns do ensino regular, pouco investimento para torná-las acessíveis, falta de profissionais especializados e outros empecilhos encontrados no dia a dia dessas instituições.

Mesmo com os obstáculos, há registro de matrícula de alunos PAEE em todas as modalidades de ensino. De acordo com os dados do Censo Escolar de 2017, o número de matrículas de estudantes PAEE no ensino infantil foi de 91.394; no ensino fundamental, de 837.993; e no ensino médio, de 116.287 (Brasil. Inep, 2018a).

E notável a lacuna que há entre as três etapas da educação básica, dado que demonstra a necessidade de se garantir a oferta de vagas a esses estudantes. Embora no Brasil as diretrizes que versam sobre educação especial e atendimento educacional especializado (AEE) garantam que se trata de uma oferta de serviço transversal, o qual deve ocorrer em todas as etapas de ensino, os dados do Censo Escolar demonstram que ainda há a necessidade de ampliação do número de matrículas para esses alunos no ensino infantil e médio, mas que as expectativas são positivas, visto que o quantitativo de estudantes PAEE na educação básica da rede regular continua crescendo (Brasil. Inep, 2018b).

Ao longo dos anos, a quantidade de discentes PAEE que cursam o ensino médio vem, gradativamente, aumentando, passando de 57.754, em 2014, para 116.287, em 2018 - o número de matrículas nessa etapa apresentou os índices mais elevados de crescimento (Brasil. Inep, 2018b). Apesar de não existirem números atualizados, os dados relacionam também as matrículas do ensino superior. 
Os institutos federais de educação (IFs) têm se destacado no contexto da educação pública devido à verticalização do ensino na educação profissional e tecnológica, com cursos que englobam o ensino médio integrado, cursos técnicos, cursos tecnológicos de nível superior, licenciaturas e pós-graduação. Sua configuração também se diferencia em relação às possibilidades de apoio ao estudante PAEE, sendo política dos IFs a criação de núcleos de apoio.

Desde 2016, o ingresso desses discentes no contexto dos IFs é realizado por meio de editais de seleção com previsão de reserva de vagas específicas para alunos com deficiência relacionada à vulnerabilidade social e a outras características historicamente excluídas, por meio da Lei no 12.711/2012 (Brasil, 2012). A esta foi acrescida a inclusão das pessoas com deficiência no público-alvo mediante o art. $5^{\circ}$ da Lei $\mathrm{n}^{\circ} 13.409 / 2016$, fator que possibilitou a ampliação de matrículas de estudantes PAEE no contexto dos institutos (Brasil, 2016). Apesar disso, ainda não se pode mensurar por números, pois os dados estatísticos nacionais não englobaram os IFs de forma discriminada em seus relatórios.

Foi prevista no contexto dos IFs a atuação dos Núcleos de Apoio às Pessoas com Necessidades Educacionais Específicas (Napnes). Estes foram idealizados e propostos no Programa Educação, Tecnologia e Profissionalização para Pessoas com Necessidades Educacionais Específicas (TEC/NEP), tendo como objetivo "criar cultura de educação para convivência, aceitação da adversidade, para eliminação das barreiras arquitetônicas atitudinais e educacionais" (Vieira, 2006, p. 14).

Tomando a educação especial como uma modalidade que deve estar presente em todos os níveis de ensino em que haja alunos PAEE, verifica-se que a concepção sobre os estudantes atendidos pelos Napnes varia entre os IFs. Há institutos federais que atendem alunos de ensino médio, considerando a educação inclusiva como algo muito mais amplo. Esse conceito contempla, além de discentes PAEE, aqueles com "distúrbios de aprendizagem, transtornos (globais do desenvolvimento e psiquiátricos) e anciãos em situação de vulnerabilidade educacional" (Nascimento; Portes, 2016, p. 83). De acordo com Mendes (2006), a ideia dessa "ampliação" do público atendido na rede federal pode ser notada, inclusive, pela determinação de que os núcleos de acessibilidade, como o Napne, coordenem ações inclusivas e busquem promover o ingresso, a permanência e o êxito dos estudantes PAEE, envolvendo a construção de uma cultura de convivência, respeito a diversidades e eliminação de barreiras educacionais e atitudinais para, assim, resultar na inclusão social e educacional dos alunos, como previsto no Decreto $n^{0}$ 7.611/2011 (Brasil, 2011). Dessa forma, este artigo tem como objetivo analisar a atuação dos núcleos relacionada aos discentes PAEE.

O Napne, nos IFs, desenvolve atividades que consistem em encontros, palestras formativas e parcerias com profissionais e organizações que trabalhem com inclusão social e educacional, orientações e auxílios aos campi, bem como elabora documentos que buscam assegurar os direitos dos estudantes PAEE. 
Outra diferença existente entre os Napnes é a composição dos núcleos.

Há IFs que preveem determinados profissionais para atuarem no núcleo, como pedagogos, psicólogos, assistentes sociais e demais profissionais do setor pedagógico; professores; profissionais de apoio escolar; guiaintérprete educacional; tradutor-intérprete de Língua Brasileira de Sinais (Libras); e o próprio docente do apoio educacional especializado. Outros simplesmente não indicam previamente nenhuma formação específica.

O aluno PAEE recebe, na maioria dos IFs e no Instituto Federal de Educação, Ciência e Tecnologia de São Paulo (IFSP), o apoio do Napne. O IFSP possui em sua constituição diferentes profissionais da Coordenadoria Sociopedagógica (CSP), docentes de várias áreas e, em alguns campi específicos, professores com formação em educação especial. Porém, estes profissionais não atuam na função de oferecer o AEE, mas ministram aulas para as diferentes licenciaturas.

Na maioria dos IFs, ainda existe o questionamento sobre a falta do AEE previsto na Política Nacional de Educação Especial na Perspectiva da Educação Inclusiva. De acordo com essa política, para garantir os direitos dos alunos nesse contexto, é obrigatória a presença da figura do professor de educação especial. Fato que faz com que muitos núcleos, mesmo com pessoas comprometidas, tenham lacunas de formação relacionadas à acessibilidade para o estudante PAEE. Outro fator importante é que os alunos têm ingressado no ensino médio e superior com deficiências de escolarização, como o não conhecimento de Braille, Libras, uso de recursos de tecnologia assistiva etc.

A política prevê ainda a "transversalidade da modalidade de educação especial desde a educação infantil até a educação superior" e a oferta do "atendimento educacional especializado" (Brasil. MEC, 2008a, p. 13), assim como entende que, para oferecer esse apoio, é necessário que o professor tenha

[...] como base da sua formação, inicial e continuada, conhecimentos gerais para o exercício da docência e conhecimentos específicos da área. Essa formação possibilita a sua atuação no atendimento educacional especializado, aprofunda o caráter interativo e interdisciplinar da atuação nas salas comuns do ensino regular, nas salas de recursos, nos centros de atendimento educacional especializado, nos núcleos de acessibilidade das instituições de educação superior, nas classes hospitalares e nos ambientes domiciliares, para a oferta dos serviços e recursos de educação especial. (Brasil. MEC, 2008a, p. 13).

Compreende-se que esses docentes são peças fundamentais não somente para o apoio em sala de recursos multifuncionais (SRM), que inclusive não foi prevista nos IFs nem teve financiamento de aquisição de materiais, mas para o trabalho em parceria com o professor da sala comum por meio da proposta de ensino colaborativo.

O trabalho baseado no ensino colaborativo, também conhecido como coensino, entre professores de educação especial e da sala regular, faz parte da proposta de alguns países para a inclusão escolar de alunos com deficiência, sendo esta apontada como uma das mais relevantes. No Brasil, esse modelo não é conhecido e/ou realizado pela maioria dos 
municípios, sendo utilizado apenas em casos pontuais e experimentais. (Vilaronga; Mendes, 2014, p. 142).

Vale destacar que muitos professores responsáveis pelas disciplinas técnicas da formação profissional se tornam docentes após o ingresso por concurso, mas não possuem formação em licenciatura. Esse fato faz com que estratégias de ensino em parceria sejam necessárias para garantir o direito dos estudantes, não só PAEE, mas da sala como um todo. Em relação ao financiamento, os Napnes também não fizeram parte daquele concedido ao Programa de Acessibilidade na Educação Superior (Incluir) ${ }^{1}$, ou seja, não foram contemplados nas políticas públicas para esse nível de ensino.

\section{O IFSP foi}

[...] constituído pela Lei $\mathrm{n}^{\circ} 11.892$, de 29 de dezembro de 2008, possui como escopo os serviços educacionais destinados à educação profissional e tecnológica, a distância e educação de jovens e adultos (Proeja), em diferentes níveis de ensino (básico, técnico e superior), formas de articulação (integrado, concomitante e subsequente) e modalidades. (IFSP, [2019a], p. 29).

Alguns campi funcionavam anteriormente à implementação da estrutura de IF, originando-se historicamente com a "Escola de Aprendizes Artífices de São Paulo, posteriormente Liceu Industrial de São Paulo, Escola Industrial de São Paulo, Escola Técnica de São Paulo, Escola Técnica Federal de São Paulo e Centro Federal de Educação Tecnológica de São Paulo" (IFSP, [2019a], p. 29). Outros são parte de um programa de expansão após 2008, espalhados por capital, litoral e interior desse estado, totalizando $37 \mathrm{campi}$ em atividade, alguns funcionando como campus avançado.

A atuação do IFSP com alunos atendidos em suas diferenças está estabelecida em seus documentos oficiais, sendo o Napne regulamentado na Resolução $n^{\circ}$ 137/2014, com previsão de implantação dos campi do IFSP, tendo como objetivos:

I. Criar a cultura da educação para a convivência, o respeito à diversidade, a promoção da acessibilidade arquitetônica, bem como a eliminação das barreiras educacionais e atitudinais, incluindo socialmente a todos por meio da educação.

II. Prestar apoio educacional aos estudantes com deficiência, com transtorno do espectro autista e com altas habilidades/superdotação do campus.

III. Difundir e programar as diretrizes de inclusão dos estudantes com deficiência, com transtorno do espectro autista e com altas habilidades/ superdotação no campus.

IV. Integrar os diversos segmentos que compõem a comunidade escolar para desenvolver sentimento de corresponsabilidade na construção da ação educativa de inclusão no IFSP (aprovado pela Resolução ${ }^{\circ}{ }^{137}$, de 4 de novembro de 2014).

V. Promover a prática democrática e as ações inclusivas para estudantes com deficiência, com transtorno do espectro autista e com altas habilidades/superdotação como diretrizes do campus. (IFSP, 2014, p. 1-2). 
Esse documento ainda relaciona a atuação com os alunos PAEE, enfatizando, no art. $6^{\circ}$, que "constitui-se público-alvo das ações inclusivas do Napne de cada campus os estudantes com necessidades educacionais específicas que se originam em função de deficiência, transtorno do espectro autista e de altas habilidades/superdotação" (IFSP, 2014, p. 3).

É prevista a composição do núcleo por eleição, tendo mandato de dois anos, formado por profissionais da Coordenadoria Sociopedagógica - um pedagogo, um assistente social, um psicólogo e um técnico em assuntos educacionais. Além desses profissionais,

[...] podem participar outros servidores do IFSP (docentes e técnicos administrativos) e pessoas da comunidade escolar (direção-geral, docentes, técnicos-administrativos, estudantes e familiares) que se identificam com a temática da inclusão, manifestam o desejo de participação no Napne e se dispõem a incorporarem-se nos projetos de inclusão e a desenvolver as ações da educação inclusiva no campus. (IFSP, 2014, p. 4).

Vale ressaltar que a maioria dos Napnes vivenciam a falta de um educador especial, o que muitas vezes acaba dificultando o êxito de algumas atividades. Esse profissional seria de extrema importância, considerando que a educação especial deve estar presente em todos os níveis de ensino. Ter a presença desse conhecimento específico na educação profissional é também um direito do aluno PAEE, devendo ocorrer em cursos nas redes regulares de ensino, pública ou privada, sendo que compete a essas instituições realizar as adequações que permitam o acesso das pessoas com deficiência ao ensino profissional e ao mercado de trabalho (Brasil. MEC. CNE, 2001).

Fica evidente a relevância de estudos voltados ao processo de inclusão dos alunos PAEE nos IFs, assim como às questões quanto a planejamento do ensino, acessibilidade e permanência. Diante desse contexto, o objetivo do presente trabalho foi mapear e analisar ações desenvolvidas ou vivenciadas pelas equipes dos Napnes de diferentes campi do IFSP, tendo como base a proposta de atuação do núcleo da instituição.

\section{Metodologia}

A pesquisa caracteriza-se como qualitativa, documental, sendo analisados os conteúdos da Revista Napne em Ação, que teve sua primeira edição em 2015, originada por um relatório das atividades anuais realizadas nos diferentes campi do IFSP. Foram também examinados os seguintes documentos institucionais: Resolução $\mathrm{n}^{\circ}$ 137, de 4 de novembro de 2014, e Instrução Normativa PRE/IFSP $n^{\circ}$ 1, de 20 de março de 2017, que regularizam a atuação dos Napnes.

Utilizando-se de técnicas da pesquisa documental, os dados foram tabulados em informações quantitativas e analisados qualitativamente. Todo o material foi lido e tabulado com as seguintes informações: $i$ ) dados da revista; ii) campi que participaram de cada edição; iii) público envolvido nas 
atividades (ações com alunos com deficiência, ações com alunos gerais, ações com docentes, ações com técnicos administrativos, formação da equipe Napne e público externo); iv) PAEE envolvido na ação; v) nome das ações; e vi) trechos do relatório que exemplificam as ações. A mesma atividade vivenciada nos campi pode ter sido enquadrada em diferentes categorias.

Em termos gerais, foram analisadas 302 páginas da revista (Tabela 1).

\section{Tabela 1 - Quantidade de páginas da revista e campi participantes}

\begin{tabular}{l|c|c|c|c|c|}
\hline \multicolumn{1}{c|}{ Ano do relatório } & 2015 & 2016 & $\mathbf{2 0 1 7}$ & $\mathbf{2 0 1 8}$ & $\mathbf{2 0 1 9}$ \\
\hline $\begin{array}{l}\text { Quantidade de páginas da } \\
\text { revista }\end{array}$ & 60 & 70 & 62 & 59 & 51 \\
\hline $\begin{array}{l}\text { Quantidade de campi } \\
\text { participantes }\end{array}$ & 19 & 23 & 19 & 24 & 21 \\
\hline
\end{tabular}

Fonte: Elaboração própria.

Nenhuma revista teve relatos de todos os campi - isso não significa que não houve atividades, mas sim que elas não foram descritas e enviadas para publicação na data solicitada pela organização da revista. A participação dos campi na elaboração do relatório que dá origem à revista, também não regular, mostra que: das 37 instituições que compõem o IFSP, 31 relataram pelo menos uma atividade realizada entre 2015 e 2019, como mostra o Gráfico 1.

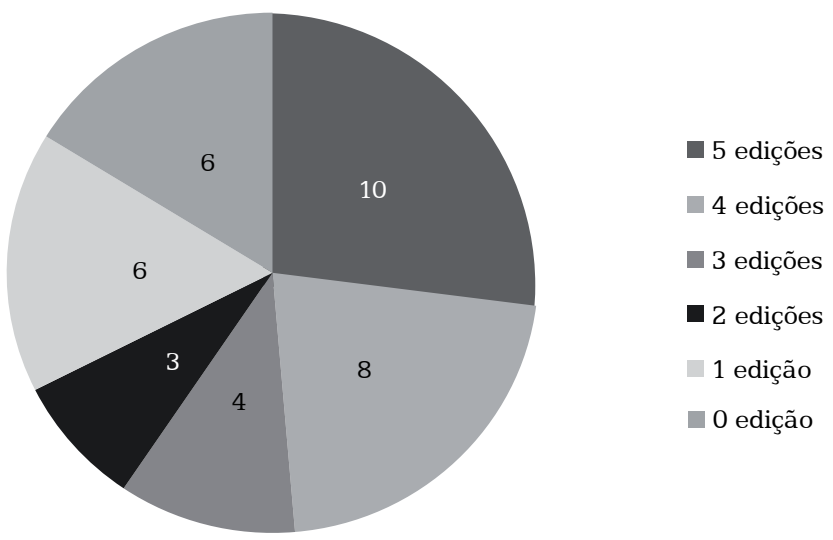

\section{Gráfico 1 - Participação dos campi do IFSP}

Fonte: Elaboração própria.

Santos (2020), ao analisar as resoluções do Napne, percebeu uma ausência de uniformização no atendimento dos núcleos do Brasil, que pode ter sido resultado do processo de implementação destes ou da mudança de membros no decorrer dos anos. Observou ainda que há núcleos muito 
atuantes e núcleos que só existem na resolução. Essa diferenciação de atuação pode ser observada também em uma mesma instituição, com base nos dados da pesquisa, quando se verificam núcleos que relataram diferentes atividades em todas as versões da revista e outros, em apenas uma ou duas edições.

Em uma análise inicial do material, percebe-se que, em 2015, a revista apresenta relatos curtos, com fotos e materiais ilustrativos em tamanhos grandes. É importante destacar que a primeira edição da revista foi apenas um ano após a regulamentação do Napne no IFSP de 2014 (IFSP, 2014). Em 2016 e 2017, foi notável o aumento de textos com relatos dos campi publicados na revista. Em 2018 e 2019, o material passou a ser composto por textos longos, e as fotos exemplificativas, que tomavam a metade da folha, na sua maioria, passaram a ser parte do texto, publicadas em tamanho pequeno.

Em relação à elaboração, na edição de 2015, a revista informa que o material foi organizado pela Diretoria de Projetos Especiais da Pró-Reitoria de Ensino (PRE). Na edição de 2016, existem apenas informações de ações desenvolvidas pela PRE. Dentre estas, estão, por exemplo, a "realização do encontro das equipes da Coordenadoria Sociopedagógica; Construção da proposta da Instrução Normativa; Capacitação Interna aos servidores, principalmente aos envolvidos com as ações do Napne no campus, por meio do curso IFSP para Tod@s" (IFSP, 2016, p. 3).

Em 2018, é anunciado que a "Revista Napne em Ação é uma organização da Coordenadoria de Ações Pedagógicas e Inclusivas, da Pró-Reitoria do IFSP" (IFSP, 2018, p. 4), com um pequeno texto de prefácio escrito pelo Pró-Reitor de Ensino Reginaldo Vitor Pereira. Em 2019, a revista não traz informações sobre sua vinculação com o setor da reitoria nem sobre quem se responsabiliza por esse periódico. Porém, sabe-se que em uma restruturação da PRE a nomeada Assessoria de Ações Inclusivas começa a fazer parte do Departamento de Articulação Pedagógica, Ações Inclusivas e Formação Continuada (Dape).

Para o trabalho, foram consideradas apenas ações relacionadas ao tema ou ao estudante PAEE; aquelas que envolveram, por exemplo, prevenção ao câncer, suicídio, adolescência, dislexia, trote solidário etc., não foram analisadas.

\section{Mapeamento das ações desenvolvidas ou vivenciadas pelas equipes dos Napnes}

Antes de examinar as atividades dos campi do IFSP, optou-se por trazer a análise das ações da PRE envolvendo o público atendido pelo Napne: encontro de tradutores e intérpretes de Libras do IFSP; participação da equipe em Fórum Distrital em Educação Profissional e Tecnológica Inclusiva em Brasília; e discussão sobre a Política de Educação Inclusiva 
durante o Congresso de Educação Tecnológica do IFSP. Diante das ações apresentadas, acredita-se que foi um ano formativo para a equipe da reitoria e de entendimento do papel do Napne, bem como dos direitos dos alunos atendidos pelo núcleo.

Na revista de 2016, são anunciadas as ações desenvolvidas pela PRE, mas sem detalhamento. É perceptível a mudança das ações descritas no periódico, de atividades formativas da equipe e entendimento coletivo da política para ações diretas com os campi, a partir do que se acredita ser o início significativo da chegada de alunos PAEE. São exemplos de atividades realizadas pela PRE:

\begin{abstract}
Realização do encontro das equipes da Coordenadoria Sociopedagógica; Construção da proposta da instrução normativa; Capacitação interna aos servidores, principalmente aos envolvidos com as ações do Napne nos câmpus, por meio do curso IFSP para Tod@s; Tradução do edital do processo seletivo em Libras; Comissão de Acessibilidade; Construção do Relatório Anual Napne em Ação 2016; Reuniões por videoconferência para orientação e construção de conhecimento junto aos campi, com a presença dos representantes, secretários e demais profissionais que atuam nos Napnes do IFSP. Além disso, houve orientações aos câmpus para atendimento a demandas específicas apresentadas por estes. (IFSP, 2016, p. 3).
\end{abstract}

A Revista de 2017 não apresenta ações da reitoria, mas anuncia que "o compromisso do IFSP com a educação inclusiva também está assegurado pelo Plano de Desenvolvimento Institucional. Nesse documento estão descritas as metas para garantir o acesso, a permanência" (IFSP, 2017, p. 3). Em uma página de apresentação, é anunciado que o periódico se destina a relatar as ações dos campi.

Na apresentação da revista de 2018, fala-se do propósito do IFSP em um texto parecido com o do ano anterior. Escreve-se que esta se destina às ações dos campi, com o pressuposto de que "acreditamos que a inclusão começa com a proximidade do outro, conhecendo sua realidade, suas capacidades e habilidades e oferecendo a oportunidade de desenvolvê-las" (IFSP, 2018, p. 3). São trazidas ações realizadas pela Coordenadoria de Ações Pedagógicas e Inclusivas (Capi) em três páginas no final da revista, mas nem todas relacionadas ao PAEE, por exemplo: encontro dos psicólogos do IFSP; discriminação de gênero e assédio sexual; noções básicas acerca do comportamento suicida; e justiça restaurativa no contexto escolar. É apresentada apenas uma ação relacionada diretamente ao público: aspectos da inclusão do estudante com deficiência intelectual (DI). Percebe-se que esse movimento sobre o público atendido no Napne é ambíguo, apesar de os documentos oficiais definirem que o núcleo tem como objetivo trabalhar com os alunos PAEE. Essa ampliação é presente não somente nos relatos dos campi, mas também nas ações elencadas pelo setor responsável na PRE.

Em 2019, a revista traz em sua apresentação um texto parecido com o das edições de 2018 e de 2017 e não são demonstradas ações da PRE. 


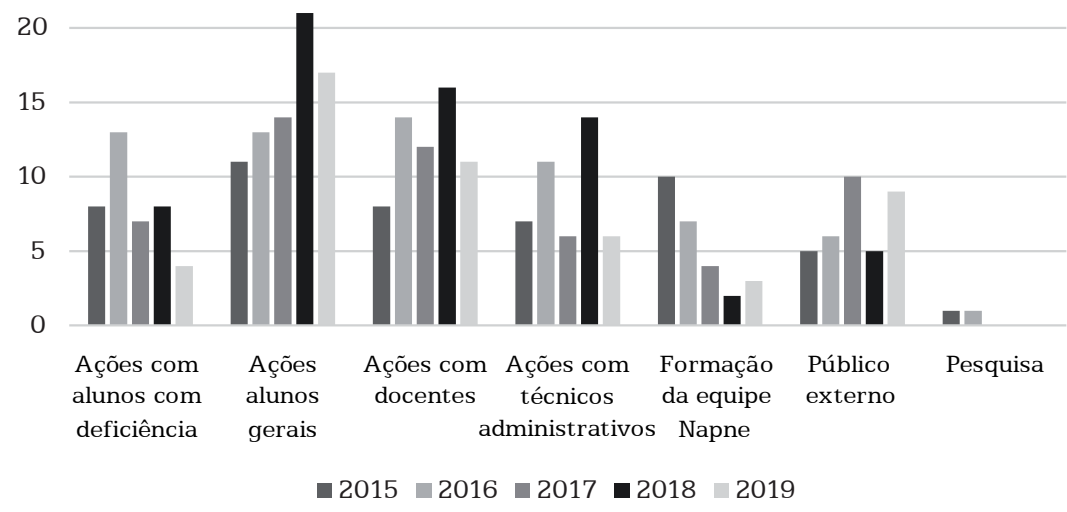

\section{Gráfico 2 - Público relatado nas ações dos Napnes}

Fonte: Elaboração própria.

A maioria das atividades relatadas no Gráfico 2 envolveu ações para os estudantes do campus, desenvolvidas em sala e extraclasse. Destacam-se as formações para os licenciados e aquelas em cursos e disciplinas de Libras. Em relação ao público externo, a participação relatada foi de pais, professores, alunos de outras escolas, pessoas PAEE do município ou instituições que trabalham com estudantes com deficiência. Ações apenas com os alunos com deficiência foram mais descritas no ano de 2016, com atividades relacionadas à adaptação de materiais, a entrevistas com os discentes e à acessibilidade da estrutura física. Nos outros anos, percebeu-se que os alunos participaram das ações do campus, mas não se destacava o estudante PAEE, o que, no ponto de vista das autoras, foi um movimento interessante de empoderamento nesse momento.

Verificou-se, também em 2016, o forte movimento de formação da equipe do Napne, com relatos de participação dos membros em eventos e cursos de outras instituições, visitas técnicas e formações in loco, mas somente para a equipe. Fato que não é observado tão fortemente nos anos subsequentes, em que existiram formações nas diferentes temáticas oferecidas em parceria com instituições externas, tendo como foco, em sua maioria, a comunidade escolar.

Não são relatadas ações específicas para os técnicos administrativos do campus, mas é feita menção a eles naquelas que envolveram os docentes e os estudantes, assim como é citada a abertura para o público externo, em sua maioria docentes de outras instituições, nas atividades de formação continuada. Como público externo também foram relatadas visitas de alunos aos campi e a atuação em parceria com instituições especializadas.

Ações de pesquisa relacionadas à pessoa com deficiência são verificadas em 2015 e em 2016. Inúmeras delas envolvem todo o público PAEE, mas algumas fazem referência a uma especificidade, com um número expressivo para a acessibilidade do estudante surdo. Não se pode afirmar, sem o acesso aos dados dos alunos matriculados, que esse público é o que teve 
mais matrículas nos últimos anos nos campi, mas, pelos relatos analisados, percebe-se que a presença do professor de Libras e do tradutor-intérprete em Libras - Língua Portuguesa como principais responsáveis pelas ações pode ter influenciado na quantidade expressiva destas para esse público.

Outro fator de destaque é o baixo número de ações relacionadas aos alunos com deficiência intelectual, o que não corrobora com a busca pelos campi nos últimos anos, indicando o aumento das matrículas desses estudantes e a procura por parcerias com os especialistas para pensar na acessibilidade para tal público. Embora não existam números para mensurar as matrículas específicas desses estudantes, tal dado traz questionamentos sobre se realmente os alunos com deficiência intelectual não estão matriculados na instituição ou se as ações para eles não têm sido mencionadas para preservar sua identidade.

Outro dado relevante é o baixo número de ações relacionadas aos discentes com altas habilidades e/ou superdotação. Existe o pressuposto de que esses estudantes estão presentes no campus, mas que não possuem a identificação como público, o que acontece também na maioria das escolas do País. A estrutura do IFSP possibilitaria diferentes trabalhos de pesquisa, de ensino de línguas e de projetos de ensino realizados por esses estudantes, o que mostra a importância de identificar as necessidades de estimulação desse público.

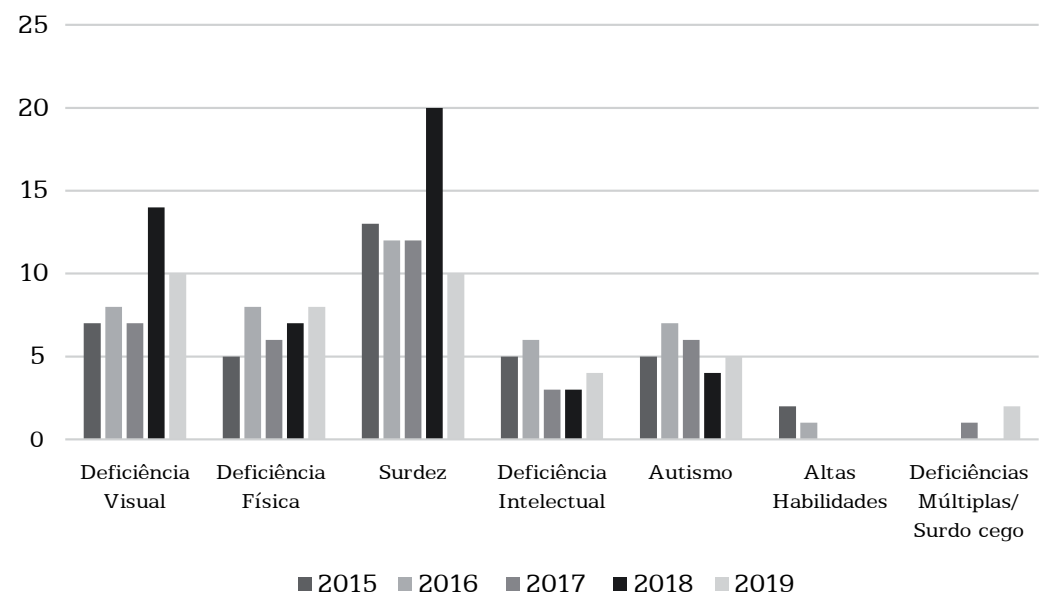

Gráfico 3 - Especificidade do estudante PAEE

Fonte: Elaboração própria.

Em relação aos temas das formações realizadas no contexto do IFSP, Gráfico 3 e Tabela 2, a discussão sobre concepção de deficiência e ações que destacavam a luta pelo rompimento do preconceito mostra o movimento inicial sobre inclusão escolar em alguns dos campi pesquisados. Entende-se que, conforme a comunidade escolar se empodera, essas ações são substituídas por estratégias de ensino, de desenho universal da aprendizagem, de recursos do espaço desses estudantes no mercado de trabalho etc. 
Tabela 2 - Temas das formações continuadas oferecidas nos campi

\begin{tabular}{|c|c|c|c|c|c|c|}
\hline & 2015 & 2016 & 2017 & 2018 & 2019 & Soma \\
\hline $\begin{array}{l}\text { Concepção } \\
\text { de deficiência } \\
\text { e quebra de } \\
\text { preconceito }\end{array}$ & 10 & 13 & 8 & 15 & 11 & 57 \\
\hline $\begin{array}{l}\text { Acessibilidade } \\
\text { curricular, } \\
\text { educação física } \\
\text { adaptada e } \\
\text { adaptação de } \\
\text { materiais }\end{array}$ & 5 & 11 & 3 & 14 & 12 & 45 \\
\hline $\begin{array}{l}\text { Relato de pessoa } \\
\text { com deficiência }\end{array}$ & 7 & 4 & 7 & 10 & 8 & 36 \\
\hline $\begin{array}{l}\text { Contextualização } \\
\text { social e política }\end{array}$ & 5 & 7 & 5 & 10 & 7 & 34 \\
\hline $\begin{array}{l}\text { Formação em } \\
\text { Libras }\end{array}$ & 7 & 3 & 4 & 10 & 5 & 29 \\
\hline $\begin{array}{l}\text { Direito da pessoa } \\
\text { com deficiência }\end{array}$ & 7 & 5 & 4 & 6 & 1 & 23 \\
\hline $\begin{array}{l}\text { Tecnologia } \\
\text { assistiva }\end{array}$ & 2 & 7 & 2 & 7 & 4 & 22 \\
\hline $\begin{array}{l}\text { Mercado de } \\
\text { trabalho para } \\
\text { pessoa com } \\
\text { deficiência }\end{array}$ & 1 & 2 & 1 & 4 & 2 & 10 \\
\hline $\begin{array}{l}\text { Esclarecimento } \\
\text { sobre o Napne }\end{array}$ & 4 & 3 & 0 & 0 & 0 & 7 \\
\hline $\begin{array}{l}\text { Diagnóstico e } \\
\text { características do } \\
\text { estudante PAEE }\end{array}$ & 1 & 0 & 0 & 1 & 2 & 4 \\
\hline $\begin{array}{l}\text { Plano Educacional } \\
\text { Individualizado } \\
\text { (PEI) }\end{array}$ & 0 & 0 & 0 & 2 & 2 & 4 \\
\hline Sorobã e Braille & 0 & 1 & 1 & 1 & 1 & 4 \\
\hline
\end{tabular}

Fonte: Elaboração própria. 
Ações referentes à educação física adaptada e às paraolimpíadas foram intensificadas em 2018 e 2019, o que pode ser relacionado com a expansão do ensino médio integrado e com a entrada do professor de educação física no contexto dos campi.

Relato de história de vida e de trajetória escolar da pessoa com deficiência ou protagonismos nas formações em diferentes temas sobre profissões e atuação profissional se intensificaram de 2017 a 2019, principalmente com ações ministradas por pessoas da comunidade local ou por profissionais de referência vinculados a instituições públicas de ensino. Trazer para a instituição pessoas com deficiência empoderadas e com formação política pode contribuir para a valorização desse público, com a discussão de que a sociedade e a escola não são acessíveis em muitos contextos, e para a quebra da relação entre a deficiência biológica e as incapacidades, as quais são oriundas de barreiras físicas e atitudinais, em sua maioria.

Formações relacionadas ao Plano Educacional Individualizado (PEI) aparecem nos dois últimos anos analisados, ainda em pequena quantidade. Fato ocasionado pela publicação da Instrução Normativa PRE/IFSP $n^{\circ}$ 1, de 20 de março de 2017, que institucionaliza o PEI no IFSP como "um documento que contém as informações sintetizadas, obtidas pela CSP e Napne, assim como o planejamento do trabalho pedagógico a ser desenvolvido" (IFSP. PRE, 2017, p. 3).

Nas ações sobre o PEI, percebe-se a presença dos docentes e da equipe do Napne como proponente, por exemplo, "a primeira configurou uma ação formativa, reunindo docentes do campus, com discussões pautadas por dados estatísticos relacionados aos estudantes com necessidades específicas matriculados na instituição" (IFSP, 2019b, p. 31-32). Assim como os dados encontrados na pesquisa de Santos (2020), observa-se, pelas ações sobre o tema relatado, a ausência da participação efetiva do estudante PAEE e de sua família, apesar de entender que não existiu o fornecimento de informações por parte desses.

Ressalta-se a importância de discutir a relação do PAEE com o mundo do trabalho, com ações não só formativas, mas com o papel social da extensão em busca da valorização da formação profissional e da ocupação de cargos equivalentes a ela. Não foram consideradas ações que envolvessem somente questões raciais, câncer de mama, câncer de próstata, doença sexualmente transmissível (DST), alunos INSS, sem que tivessem relação direta com os estudantes PAEE.

A título de exemplificação, foram destacadas no Quadro 1 algumas ações dos Napnes IFSP quanto às competências previstas, porém, no material analisado, observou-se um número elevado de ações dos núcleos nesses cinco anos, como evidenciado anteriormente. 


\section{Quadro 1 - Exemplos de ações relacionadas às competências do Napne IFSP na Revista Napne em Ação}

(continua)

Das competências do Napne IFSP (2014)

I. Promover a autonomia dos estudantes com deficiência, com transtorno do espectro autista e com altas habilidades/ superdotação ao estabelecer estratégias para promoção da superação e remoção de barreiras atitudinais, arquitetônicas, pedagógicas e comunicacionais no campus.

\section{Mediar as relações} entre as famílias, o campus e as instituições especializadas que atendam os estudantes com necessidades educacionais específicas que se originam em função de deficiência, de transtorno do espectro autista e de altas habilidades/ superdotação.

\section{Estabelecer} parcerias do campus com as instituições especializadas e com a rede de serviços públicos municipal, estadual e federal, para atendimento dos estudantes público-alvo da educação especial.
Exemplos de ação descrita na Revista Napne

"Desmistificando a Língua de Sinais - em fevereiro de 2018, São Carlos recebeu a primeira aluna surda do campus. Ingridy Nazario está cursando o Técnico em Informática para Internet integrado ao ensino médio e realizou uma apresentação especial em sua aula de português. A apresentação abordou o tema da surdez e os diversos aspectos que envolvem o mundo do surdo. Os pontos foram trabalhados em forma de mitos que foram sendo desvendados em diálogos com seus colegas". (IFSP, 2018, p. 45).

"O Napne Campus São Paulo, desde 2018, organiza um grupo de familiares de alunos com transtornos do espectro autista (TEA). Embora seja um grupo para familiares, até agora, apenas mães frequentaram as reuniões que ocorrem bimestralmente. Nesses encontros, a equipe do Napne apresenta materiais sensibilizadores para discussão, tais como vídeos e documentários sobre o cotidiano da pessoa com TEA. A partir disso, são promovidas trocas de experiências nas quais as mães podem compartilhar suas dificuldades e aprendizados na educação e convívio com seus filhos." (IFSP, 2019b, p. 44).

Campus Araraquara - foco, em 2016, foi o estreitamento da relação do campus com a comunidade de deficientes. Foi feita uma parceria com a Assessoria Especial para pessoas com deficiência do município para identificar demandas, preparar a instituição para o atendimento do deficiente e realizar a oferta de cursos direcionados a essa população, além de identificar as necessidades de produção de tecnologia assistiva. Também ocorreram diversas palestras, oficinas, relatos de experiência e minicursos sobre inclusão, destacando-se a palestra da coordenadora da Assessoria Especial para pessoas com deficiência do município, na semana de planejamento, a Semated, em maio, com o tema "Educação Especial e Tecnologias", com colaboração de diversos convidados com ampla experiência sobre inclusão, e o "Setembro Azul", em comemoração ao Dia Nacional do Surdo, quando ocorreram diversas apresentações de membros da comunidade de surdos. (IFSP, 2016, p. 04). 
Das competências do Napne IFSP (2014)

IV. Propor, estimular e acompanhar a implementação

de acessibilidade arquitetônica, atitudinal, comunicacional e pedagógica no campus para a transposição das barreiras arquitetônicas, comunicacionais, pedagógicas e atitudinais aos estudantes públicoalvo da educação especial.

\section{Estimular o} desenvolvimento de tecnologia assistiva por meio de sugestão, incentivo e/ou proposição de projetos internos e externos que visem à implementação de inovações tecnológicas inclusivas no IFSP. parcerias do campus com empresas privadas ou instituições especializadas na produção de tecnologias assistivas na circunvizinhança.

\section{Exemplos de ação descrita na Revista Napne}

"Projeto: Acessibilidade arquitetônica no campus Campos do Jordão, com a apresentação do trabalho realizado por um grupo de alunos do curso Técnico em Edificações integrado ao ensino médio. Esse trabalho foi desenvolvido para atender às demandas de acessibilidade do campus". (IFSP, 2018, p. 21)

"Campus Guarulhos - Dispositivo assistivo de transferência - os alunos Douglas Masaiti Sato e Jonas da Silva Fernandes apresentaram em 2016, como trabalho de conclusão do curso de graduação em Tecnologia em Automação Industrial, orientado pelos professores Dennis Toufen e Claudemir Alves, o projeto de dispositivo assistivo de transferência. O trabalho propôs o projeto de uma ferramenta assistiva que transfira um usuário de até $100 \mathrm{~kg}$ da cadeira de rodas para a cama e vice-versa. A ferramenta pode ser usada como cadeira de rodas pelo paciente e todo o sistema foi modelado e ensaiado virtualmente, por meio de softwares. O custo final para produção está previsto em $\mathrm{R} \$ 2.289,84$. Todas as peças mecânicas possuem medidas e formas comerciais e foram ensaiadas mecanicamente". (IFSP, 2016, p. 37).

Campus Votuporanga - em novembro passado, foi realizada, no Campus Votuporanga do Instituto Federal, a I Olimpíada de Tecnologia Assistiva para Mobilidade - Tecnomobi 2015. O objetivo do evento foi proporcionar ao cidadão portador de deficiência locomotiva maior independência, qualidade de vida e inclusão social, por meio da geração de protótipos relacionados à mobilidade, na modalidade veículos elétricos, num evento competitivo, em nível nacional. Participaram da olimpíada equipes de diversas instituições de ensino. O evento recebeu apoio do Conselho Nacional de Desenvolvimento Científico e Tecnológico (CNPq) e de empresas da região. O Napne participou, apoiando no dia do evento. A realização do evento resultou no Acordo de Cooperação com a Santa Casa de Fernandópolis, no ano de 2016. (IFSP, 2016, p. 66). 
VII. Participar de formações continuadas promovidas pelo IFSP na área de educação inclusiva.
Coordenadoria de Ações Pedagógicas e Inclusivas (Capi) - Aspectos da inclusão do estudante com DI. No dia 18 de outubro de 2018, realizamos uma reunião com representantes dos Napnes para discutir aspectos da inclusão do estudante com deficiência intelectual. Tal reunião aconteceu por videoconferência e contou com a participação da professora Fernanda M. M. G. Queiroz, da Universidade Federal da Bahia (UFBA), do departamento de Educação, área de Educação Especial e Tecnologia Assistiva. Discutiram-se questões como os desafios para incluir o aluno com deficiência intelectual, quais os tipos de adaptação possíveis, como é feito o diagnóstico etc.

Campus Avaré - Sensibilização do corpo docente e discente - o professor Eder Pires de Camargo, livre-docente no ensino de física que atua na Unesp de Ilha Solteira e mantém grupo de pesquisa em educação para PCD no Campus da Unesp Bauru, falou sobre "adaptação curricular". Convidada também para compor a mesa, a professora Maria Lúcia Garcia de Almeida do IFSP Campus Pirituba palestrou sobre "didática para inclusão". No mês de outubro, a convite novamente do Napne, o professor Eder Pires de Camargo retornou ao campus e debateu com os alunos dos cursos técnicos integrados e do superior pela manhã; no período noturno, conversou com os alunos dos cursos técnicos concomitantes/subsequentes e superiores. (IFSP, 2017, p. 5).

"No ano de 2016, o Napne de São Roque promoveu uma série de ações para melhoria das práticas pedagógicas junto a alunos com necessidades educacionais específicas e sensibilização sobre temáticas importantes junto à comunidade, no que se refere ao respeito à diversidade. Dentre as principais ações, destacou-se a participação ativa em conselhos, com orientações de práticas pedagógicas a partir de discussões de casos, realizada com a equipe a partir de solicitação dos docentes." (IFSP, 2016, p. 59). 
Das competências do Napne IFSP (2014)

X. Sugerir, apoiar, intermediar e implementar ou acompanhar a implementação de atividades/projetos inclusivos do campus para o atendimento das necessidades educacionais específicas de estudantes públicoalvo da educação especial.

XI. Sugerir, participar de construções coletivas, implementar ou acompanhar a implementação de políticas públicas de inclusão do IFSP no campus.

\section{Participar de} eventos correlatos à área da inclusão social que se julgarem necessários e dos que versem sobre a temática da inclusão educacional de estudantes públicoalvo da educação especial com necessidades educacionais específicas.
Exemplos de ação descrita na Revista Napne

Ação de acessibilidade - no primeiro semestre de 2018, o IFSP - Campus Presidente Epitácio recebeu seu segundo estudante com nanismo. Como parte das adaptações necessárias, o Napne em conjunto com a Coordenadoria de Manutenção, Almoxarifado e Patrimônio (CAP) do campus confeccionaram duas plataformas de madeira com degraus para facilitar o acesso do estudante ao lavatório dos banheiros. A princípio, o Napne entrou em contato com o estudante para identificar suas necessidades e realizar as medições para a construção da plataforma. Em seguida, a CAP realizou a marcenaria e a pintura, deixando-a como na foto. O campus já conta com outra plataforma para acesso desses estudantes aos maquinários dos Laboratórios de Elétrica. (IFSP, 2018, p. 40).

O Napne Piracicaba, por meio de uma parceria com a Secretaria Municipal de Trânsito e Transportes (Semuttran) de Piracicaba, deu ínicio as suas ações em 2016, através da demarcação das vagas preferenciais do estacionamento do campus. Idosos e pessoas com deficiência têm direito a vaga preferencial garantida em lei, e essa preferência agora está demarcada em locais de fácil acesso aos blocos, nas dependências do campus. (IFSP, 2016, p. 48).

A $8^{a}$ edição da Caravana da Inclusão, Acessibilidade e Cidadania, realizada em agosto, foi no Campus Barretos. A ação contou com a presença de diversas autoridades, como o Secretário Adjunto de Estado dos Direitos da Pessoa com Deficiência de São Paulo, Luiz Carlos Lopes, coordenador da Caravana; a Secretária Municipal de Assistência Social e Desenvolvimento Humano de Barretos; o Defensor Público da $1^{a}$ Defensoria Pública da Unidade de Barretos, Dr. Gustavo Santos, entre outros. O evento foi realizado pela Secretaria Estadual dos Direitos da Pessoa com Deficiência, com o tema central "O papel do Ministério Público e da Defensoria Pública na garantia dos direitos da pessoa com deficiência". O objetivo foi demonstrar quais são as ações e os mecanismos legais, no âmbito da estrutura de cada uma dessas duas instituições, pelos quais a população com deficiência pode encaminhar suas demandas não atendidas tendo em vista as barreiras físicas, comunicacionais e atitudinais encontradas em seu dia a dia. (IFSP, 2017, p. 8-9). 
XIII. Planejar e desenvolver, anualmente, atividades de ações inclusivas para as comunidades interna e externa, de forma que constem no calendário oficial do campus, independentemente de matrícula de estudantes público-alvo da educação especial.
Semana de educação inclusiva - de 25/9 a 29/9 comemoramos a IV Semana de Educação Inclusiva, e no dia 25 de setembro os eventos ocorreram no IFSP - Campus Matão. Tivemos várias apresentações como: roda de conversa: "Adaptação em todos os ambientes", com Alex José Sabino; vôlei sentado para ensino médio e graduação (no Sesi); palestra "Escolarização e o mercado de trabalho para pessoas com deficiência visual", com Luiz Guilherme Palácio e Fábio Deodato; mostra de materiais didáticos adaptados e mostra de vídeos e vivências confeccionados pelos alunos do $6^{\circ}$ semestre de Licenciatura de Química do IFSP Campus Matão. Contamos com a participação de docentes, discentes e técnicos administrativos. (IFSP, 2017, p. 28).

\section{Orientar e}

auxiliar os docentes do campus quanto ao processo de inclusão de estudantes público-alvo da educação especial com necessidades educacionais específicas.
Campus Jacareí - Troca de experiências didáticas inclusivas - esse evento, em horário de formação continuada, possibilitou que os profissionais da educação agregassem conhecimento relativo à adaptação e elaboração de material didático para alunos surdos. A troca de experiência contou com a presença dos docentes do próprio campus, sendo que uma parte deles apresentou materiais didáticos por eles criados e adaptados para atender uma necessidade específica do campus. (IFSP, 2018, p. 32).

Fonte: Elaboração própria.

Compactua-se com o pressuposto de que as ações de forma isolada não são a garantia de que os direitos dos alunos PAEE estão sendo observados no contexto do IFSP, mas demonstram um movimento da comunidade escolar, que, mesmo sem a situação ideal de inclusão escolar nos campi, não está estagnada desde a criação dos núcleos.

Ação contínua que também foi observada por Costa (2018). A autora entende que essa ação local em cada campus possibilita o desenvolvimento de uma cultura de ensino para a diversidade e contribui para que se pense nas adaptações necessárias para inclusão do aluno PAEE.

Porém, mesmo com a quantidade de parcerias externas feitas, segundo a revista analisada, entende-se que o contexto do IFSP ainda vivencia uma contrariedade, pois, muitas vezes, esse coletivo de profissionais do Napne, por mais qualificados que sejam em suas áreas, raramente possui formação específica em educação especial. Mesmo com a existência de profissionais com essa formação específica no núcleo, eles estão em cargos que não são de professor de AEE e não possuem força de trabalho para suprir as 
demandas e garantir os direitos assegurados ao PAEE. Todos os outros membros estão nessa mesma condição de atuação, ou seja, pelo fato de o núcleo não possuir caráter de coordenadoria, sendo impedido de realizar contratações, não há membros que possam se dedicar exclusivamente às tarefas essenciais para a real efetivação da inclusão no campus. Fato destacado na Revista Napne de 2019 (IFSP, 2019b, p. 44): "Os desafios e dificuldades continuam sendo grandes pelo elevado número de alunos atendidos no campus, pela especificidade de cada um e pela equipe reduzida, que tem que conciliar sua atuação no Napne com suas demais atribuições".

Esse fator pode ser diminuído com a implantação do Plano de Desenvolvimento Institucional (2019-2023), que prevê nos objetivos dos "Princípios Fundamentais da Política de Ações Afirmativas", além das ações mencionadas nos objetivos do Napne,

[...] a acessibilidade virtual/comunicacional de sites, portais, sistemas e ambientes virtuais de ensino-aprendizagem; a disponibilização de produtos e serviços de tecnologia assistiva para o apoio ao público-alvo da educação especial; a disponibilização de intérprete de Libras para estudantes surdos ou com deficiência auditiva, conforme a demanda e necessidade de atendimento, durante todo o percurso educacional; a disponibilização de guia-intérprete para estudante surdocego, durante todo o percurso educacional; a implantação de salas de recursos multifuncionais nos campi do IFSP, conforme a demanda e necessidade de atendimento; e a oferta de atendimento educacional especializado (AEE) aos estudantes público-alvo da educação especial que demandarem esse atendimento. (IFSP, [2019a], p. 241-242).

Entende-se que a ampliação do quadro de profissionais com formação específica para acessibilidade do aluno PAEE é uma das fontes principais de garantia dos direitos desses estudantes em contexto dos IFs.

\section{Considerações finais}

Como fechamento, parte-se do pressuposto da criação do Napne em 2014 e seus objetivos de atuação, entendendo que, com base na análise dos relatórios publicados na Revista Napne em Ação, ainda há um longo caminho a percorrer para cumprir a proposta de criação dos núcleos.

Sobre "criar a cultura da educação para a convivência, o respeito à diversidade, a promoção da acessibilidade arquitetônica, bem como a eliminação das barreiras educacionais e atitudinais, incluindo socialmente a todos por meio da educação" (IFSP, 2014), acredita-se que as ações propostas pelos núcleos caminharam nessa direção. Isso se deu na medida em que a maioria dessas ações realizaram atividades que envolveram o rompimento de barreiras atitudinais, com servidores e alunos, e quando foram relatadas algumas ações de acessibilidade física dos campi. Sabe-se que muitas construções do IFSP são novas e que já foram idealizadas com base nas regras de acessibilidade da Associação Brasileira de Normas e Técnicas (ABNT), o que aproxima a instituição de cumprir o objetivo proposto. 
Em relação a "prestar apoio educacional aos estudantes com deficiência, com transtorno do espectro autista e com altas habilidades/superdotação do campus" (IFSP, 2014), também são relatadas ações relacionadas à acessibilidade específica aos alunos PAEE, principalmente nos últimos dois anos, o que se acredita ser fruto da política de cotas e da orientação de elaboração do Plano Educacional Especializado. Destaca-se nesse aspecto a busca pela informação sobre estudantes e estratégias de ensino acessíveis em parceria com instituições externas e com profissionais com formação na área específica, principalmente no que se refere à educação de surdos e à Língua Brasileira de Sinais. Não existem dados para mensurar se esse foco na surdez tem relação com o aumento de matrículas de estudantes surdos ou com a entrada dos tradutores e intérpretes de Libras-Português no contexto do IFSP. Vale ressaltar a importância do professor de educação especial para suprir essa lacuna, evidenciada na busca pela formação, visto que esse profissional é quem pode dar, para o professor da sala comum, indícios de como atuar com o aluno PAEE, mas isso ainda não supre a demanda do trabalho colaborativo entre esses docentes.

O objetivo de "difundir e programar as diretrizes de inclusão dos estudantes com deficiência, com transtorno do espectro autista e com altas habilidades/superdotação no campus" (IFSP, 2014) foi contemplado em alguns aspectos nas ações desenvolvidas pela Pró-Reitoria de Ensino em relação à programação de diretrizes e, também, em poucas ações de difusão nos campi. Não existe base para relatar se essa lacuna existe na instituição ou se não foi abordada na Revista Napne.

Sobre "integrar os diversos segmentos que compõem a comunidade escolar para desenvolver sentimento de corresponsabilidade na construção da ação educativa de inclusão no IFSP" (IFSP, 2014), foram relatadas, em sua maioria, ações com foco na comunidade docente e nos alunos da instituição. Mesmo quando realizadas pela equipe da Coordenadoria Sociopedagógica, composta por técnicos administrativos, não se destacam ações além da quebra de barreiras atitudinais. Mais uma vez, com base nos materiais analisados, não existem dados para prever se essas ações não acontecem ou se não foram relatadas. Quanto às famílias, há uma ação em destaque sobre o tema em 2019, mas não existem dados da participação dos familiares dos alunos menores de idade, a não ser que esteja contemplado o público-alvo em ações que envolveram "toda a comunidade escolar".

Todas as ações realizadas, no ponto de vista das autoras, visaram "promover a prática democrática e as ações inclusivas para estudantes com deficiência, com transtorno do espectro autista e com altas habilidades/ superdotação como diretrizes do campus" (IFSP, 2014). Destaca-se, somente, a necessidade de os estudantes PAEE serem frente das ações, terem espaço de fala sobre eles mesmos e sobre seu futuro. Percebeu-se um movimento de fala de pessoas PAEE da comunidade externa e um movimento inicial da participação efetiva nas ações do núcleo também nos últimos dois anos, quando se acredita que ingressou a maioria dos alunos PAEE que faz parte da comunidade escolar atual.

Ou seja, mesmo estando em um contexto em que não existe financiamento específico para os Napnes, de aspectos que se destacam 
na instituição referentes a lacunas de formação docente, formação dos técnicos administrativos, falta de professores de educação especial - quem legalmente faz o AEE -, falta de tradutor-intérprete de Libras e de outros profissionais para garantir a acessibilidade de todos os alunos, falta de profissionais da CSP em alguns campi, falta de tecnologia assistiva, falta de acessibilidade física em alguns campi e falta de políticas públicas para a Rede Profissional e Tecnológica e para o IFSP, a revista traz os avanços e uma rica quantidade de ações específicas para os alunos PAEE intensificadas nos últimos anos, o que permite afirmar que a falta não foi estagnadora em muitos contextos e que a inclusão escolar tem sido assunto e prática, mesmo que em situações pontuais.

Acredita-se que a proposta de uma revista que reunisse as ações dos campi no ano posterior ao da resolução de aprovação do Napne foi assertiva, pois, apesar de poder haver ações que não foram enviadas para a publicação, aquelas que foram possivelmente serviram de exemplo e incentivo para outros campi. Outra contribuição que pode ser destacada na atual pesquisa foi o crescimento de atuações e os temas mais e menos discutidos pelos núcleos. Dados relevantes para que o Dape possa, por exemplo, considerar para o planejamento das próximas ações institucionais.

Existe, sim, um caminho a percorrer, inclusive de pesquisas sobre como vem acontecendo o processo de inclusão escolar no IFSP e em outras instituições da Rede Profissional e Tecnológica e sobre como pensar no que se espera da instituição, em um processo de construção coletiva. Por isso, espera-se que este artigo possa contribuir com as discussões sobre a inclusão escolar na Rede Profissional e Tecnológica e, especificamente, nos campi do IFSP.

\section{Referências}

BRASIL. Decreto n 7.611 , de 17 de novembro de 2011. Dispõe sobre a educação especial, o atendimento educacional especializado e dá outras providências. Diário Oficial da União, Brasília, DF, 18 nov. 2011. Seção 1, p. 12 .

BRASIL. Lei no 12.711, de 29 de agosto de 2012. Dispõe sobre o ingresso nas universidades federais e nas instituições federais de ensino técnico de nível médio e dá outras providências. Diário Oficial da União, Brasília, DF, 30 ago. 2012. Seção 1, p. 3.

BRASIL. Lei no 13.146, de 6 de julho de 2015. Institui a Lei Brasileira de Inclusão da Pessoa com Deficiência (Estatuto da Pessoa com Deficiência). Diário Oficial da União, Brasília, DF, 7 jul. 2015. Seção 1, p. 2.

BRASIL. Lei $\mathrm{n}^{\circ}$ 13.409, de 28 de dezembro de 2016. Altera a Lei $\mathrm{n}^{\circ} 12.711$, de 29 de agosto de 2012, para dispor sobre a reserva de vagas para pessoas com deficiência nos cursos técnico de nível médio 
e superior das instituições federais de ensino. Diário Oficial da União, Brasília, DF, 29 dez. 2016. Seção 1, p. 3.

BRASIL. Instituto Nacional de Estudos e Pesquisas Educacionais Anísio Teixeira (Inep). Censo Escolar 2017: notas estatísticas. Brasília, DF:

Inep, 2018a.

BRASIL. Instituto Nacional de Estudos e Pesquisas Educacionais Anísio Teixeira (Inep). Censo Escolar 2018. Brasília, DF, 2018b. Disponível em: $<$ https://sitio.educacenso.inep.gov.br/educacao-especial>. Acesso em: 13 jun. 2020.

BRASIL. Ministério da Educação (MEC). Política Nacional de Educação Especial na perspectiva da educação inclusiva. Brasília, DF: MEC, 2008a.

BRASIL. Ministério da Educação (MEC). Programa Incluir. Brasília, DF, 2008b. Disponível em: <http://portal.mec.gov.br/programa-incluir >. Acesso em: 5 abr. 2021.

BRASIL. Ministério da Educação (MEC). Conselho Nacional de Educação (CNE). Resolução CNE/CEB no 2, de 11 de setembro de 2001. Institui diretrizes nacionais para a educação especial na educação básica. Diário Oficial da União, Brasília, DF, 14 set. 2001. Seção 1E, p. 39.

COSTA, L. U. Desenvolvimento profissional de coordenadores do Napne do Instituto Federal do Acre. 2018. 177 f. Dissertação (Mestrado Profissional em Ensino Tecnológico) - Instituto Federal de Educação Ciência e Tecnologia do Amazonas, Manaus, 2018.

INSTITUTO FEDERAL DE EDUCAÇÃO, CIÊNCIA E TECNOLOGIA DE SÃO PAULO (IFSP). Resolução no 137, de 4 de novembro de 2014.

Aprova o Regulamento do Núcleo de Apoio às Pessoas com Necessidades Educacionais Específicas (Napne). São Paulo, 2014. Disponível em: $<$ https://drive.ifsp.edu.br/s/6JkADWN5Fjo6crG\#pdfviewer >. Acesso em: 1 abr. 2021.

INSTITUTO FEDERAL DE EDUCAÇÃO, CIÊNCIA E TECNOLOGIA DE SÃO PAULO (IFSP). Napne em ação: relatório de atividades 2016. São Paulo: IFSP, 2016.

INSTITUTO FEDERAL DE EDUCAÇÃO, CIÊNCIA E TECNOLOGIA DE SÃO PAULO (IFSP). Revista Napne em ação 2017. São Paulo: IFSP, 2017.

INSTITUTO FEDERAL DE EDUCAÇÃO, CIÊNCIA E TECNOLOGIA DE SÃO PAULO (IFSP). Revista Napne em ação 2018. São Paulo: IFSP, 2018.

INSTITUTO FEDERAL DE EDUCAÇÃO, CIÊNCIA E TECNOLOGIA DE SÃO PAULO (IFSP). Plano de desenvolvimento institucional 2019-2023: 
com você, planejando o futuro. São Paulo: IFSP, [2019a]. Disponível em: <https://www.ifsp.edu.br/images/pdf/PDI1923/PDI-2019-2023 Aprovado-CONSUP-12.03.2019-valendo.pdf >. Acesso em: 1 abr. 2021.

INSTITUTO FEDERAL DE EDUCAÇÃO, CIÊNCIA E TECNOLOGIA DE SÃO PAULO (IFSP). Revista Napne em ação. São Paulo: IFSP, 2019b.

INSTITUTO FEDERAL DE EDUCAÇÃO, CIÊNCIA E TECNOLOGIA DE SÃO PAULO (IFSP). Pró-Reitoria de Ensino (PRE). Instrução Normativa PRE/IFSP n ${ }^{\circ}$ 001, de 20 de março de 2017. Estabelece orientações para identificação e acompanhamento pelo Napne, dos estudantes com necessidades específicas. São Paulo, 2017. Disponível em: <https://ifsp. edu.br/ex-alunos/42-assuntos/ensino/1472-acoes-inclusivas >. Acesso em: 4 abr. 2021.

MENDES, E. G. A radicalização do debate sobre inclusão escolar no Brasil. Revista Brasileira de Educação, Rio de Janeiro, v. 11, n. 33, p. 387405, set./dez. 2006.

NASCIMENTO, F. C.; PORTES, R. M. L. A inclusão de pessoas com necessidades específicas na rede federal de educação profissional, científica e tecnológica, a partir da ação TEC/NEP: uma reflexão atual. In: BRANCHER, V. R.; MEDEIROS, B. A. (Org.) Inclusão e diversidade: repensando saberes e fazeres na educação profissional, técnica e tecnológica. Jundiaí: Paco Editorial, 2016. Cap. 6.

SANTOS, J. R. Inclusão escolar e os modos de planejamento educacional individualizado nos institutos federais brasileiros. 2020. $160 \mathrm{f}$. Dissertação (Mestrado em Educação Especial) - Centro de Educação e Ciências Humanas, Universidade Federal de São Carlos, São Carlos, 2020.

VIEIRA, S. C. A. A educação profissional e tecnológica como fator de desenvolvimento e inclusão social. In: SEMINÁRIO NACIONAL DE EDUCAÇÃO, TECNOLOGIA E PROFISSIONALIZAÇÃO PARA PESSOAS COM NECESSIDADES EDUCACIONAIS ESPECIAIS: PROGRAMA TEC/ NEP, 2006, Brasília, DF. Anais... Brasília, DF: MEC, 2006. p. 7-17.

VILARONGA, C. A. R.; MENDES, E. G. Ensino colaborativo para o apoio à inclusão escolar: práticas colaborativas entre os professores. Revista Brasileira de Estudos Pedagógicos, Brasília, DF, v. 95, n. 239, p. 139151, jan./abr. 2014.

Recebido em 7 de agosto de 2020.

Aprovado em 30 de outubro de 2020. 